\title{
A LEITURA NA BIBLIOTECA PÚBLICA DE ÉVORA: UM CONTRIBUTO PARA A HISTÓRIA DA LEITURA EM PORTUGAL (1887-1921)
}

\author{
Francisco António Lourenço Vaz* \\ Departamento de História. Universidade de Évora
}

\begin{abstract}
Resumo:A Biblioteca Pública de Évora é uma das mais importantes bibliotecas patrimoniais de Portugal, quer pela sua coleção quer por ter sido uma das primeiras bibliotecas a abrir as portas aos leitores. Neste trabalho analisam-se os dados publicados sobre a leitura na Biblioteca Pública de Évora, entre 1887-1921, em particular o número de leitores em cada ano, os livros requisitados, as temáticas mais populares, a leitura de jornais e a comparação entre a leitura pública e a alfabetização da população. Como fontes utilizam-se os dados publicados pelo Anuário Estatístico de Portugal, os livros de registo de leitores e visitantes, os relatórios dos bibliotecários e verbetes de leitura. Esta análise tem como objetivo traçar o perfil do leitor da Biblioteca Pública de Évora e contribuir para a caracterização do público leitor em Portugal na transição do século XIX para o século XX.
\end{abstract}

Palavras chave: História da lectura; biblioteca pública; bibliotecário; coleções.

Título: LECTURA EN LA BIBLIOTECA PÚBLICA DE ÉVORA: UNA CONTRIBUCIÓN A LA HISTORIA DE LA LECTURA EN PORTUGAL (1887-1921).

Resumen: La Biblioteca Pública de Évora es una de las bibliotecas más importantes del patrimonio de Portugal por la colección bibliográfica que contiene y por estar entre las primeras en abrir sus puertas a los lectores. Este trabajo trata de realizar un análisis de los datos publicados sobre la lectura en la Biblioteca Pública de Évora, entre 1887 y 1921, en particular, el número de lectores de cada año, los libros requeridos, los temas más populares, la lectura de periódicos y la comparación entre la lectura pública y la alfabetización de la población. Se han utilizado como fuentes, los datos publicados por el Anuario Estadístico de Portugal, los libros de registro de lectores y visitantes, los informes de los bibliotecarios y las entradas de lectura. Con este análisis se pretende esbozar el perfil de lector de la Biblioteca Pública de Évora y contribuir a la caracterización del público lector en Portugal en la transición del siglo XIX al siglo XX.

Palabras clave: Historia de la lectura; biblioteca pública; bibliotecario; colecciones.

\section{Title: READING IN PUBLIC LIBRARY OF ÉVORA: A CONTRIBUTION FOR THE HISTORY OF READING IN PORTUGAL (1887-1921).}

Abstract: The Public Library of Évora is one of the most important heritage libraries of Portugal, both for its collection either by being one of the first libraries to open the doors to readers. This paper analyzes the published data on reading at Public Library of Évora, between1887-1921, in particular the number of readers in each year, the required books, the most popular themes, reading newspapers and the comparison between the public reading and literacy of the population. It is use as sources the data published by the Statistical Yearbook of Portugal, readers and visitors registration books, reports from librarians and reading entries. This analysis aims to draw the profile of reader at the Public Library of Évora and contribute to the characterization of the reading public in Portugal in the transition of the nineteenth century to the twentieth century.

Keywords: History of reading; public library; librarian; collections.

\section{INTRODUÇÃO}

O autor eborense Manuel Severim de Faria, na obra Notícias de Portugal, faz um rasgado elogio à cidade de Évora, começando por apontar a sua situação geográfica «no meio da Província do Alentejo, em um posto tão eminente que fica senhoreando os campos que a cercam por toda a parte» (Severim, 2003, p. 255), e sublinha a admiração que a cidade produzia nos estrangeiros que a visitavam, a ponto de os italianos a considerarem semelhante a Roma e os castelhanos à "sua Madrid" (idem, ibidem). De facto, Évora tem uma situação geográfica privilegiada no coração da província alentejana, teve em várias ocasiões um papel determinante na História de Portugal, escolhida na época dos descobrimentos como segunda residência dos reis e procurada por muitos nobres para construir os seus solares. Não faltam em Évora monumentos que atestam a passagem e ocupação romana e depois muçulmana, a reconquista cristã e as diversas épocas da história nacional, e que a transformaram em cidade detentora de um património histórico notável, que lhe trouxe o reconhecimento da UNESCO como Cidade Património da Humanidade em 1986.

\footnotetext{
*fvaz@uevora.pt

Recibido: 16-10-2015; 2 2a versión: 26-05-2016; aceptado: 17-06-2016.
}

LOURENÇO VAZ, F.A. A Leitura na Biblioteca Pública de Évora: Um contributo para a história da leitura em Portugal (18871921). Anales de Documentación, 2016, vol. 19, nº 2. Disponible en: http://dx.doi.org/10.6018/analesdoc.19.2.239671. 
Situada no coração da cidade, próxima do Templo de Diana e ladeada pelo edifício do antigo Convento de S. João Evangelista e pelo do Museu eborense, a Biblioteca Pública é uma instituição bicentenária e uma das muitas joias do património de Évora. Foi fundada em 1805 por iniciativa do arcebispo, D. Frei Manuel do Cenáculo (1724-1814), um dos nomes mais representativos do iluminismo português, estadista no tempo do Marquês de Pombal, coleccionador e bibliófilo que tem o seu nome ligado a fundação e renovação de outras bibliotecas, nomeadamente, a do Convento de Nossa Senhora de Jesus de Lisboa, cujos fundos bibliográficos seriam depois integrados na Biblioteca da Academia das Ciências de Lisboa, a Real Biblioteca Pública e a Biblioteca Eclesiástica de Beja.

A ideia que Frei Manuel tinha de uma biblioteca, tal como a definimos em anterior trabalho ${ }^{1}$, era a de um centro de recursos ao serviço da instrução, uma biblioteca-museu, que ganha estatuto de instituição por excelência para promover o conhecimento e fundamental pra reformar a sociedade. Como homem das Luzes, Frei Manuel do Cenáculo encarava os livros como os repositórios da ciência e da verdade da religião e, em oposição àqueles que restringiam o acesso aos livros, que compara aos avarentos, defende que as bibliotecas devem estar ao serviço do público ${ }^{2}$. Mas é conveniente precisar que este público anda associado, nas obras de Cenáculo, a outros epítetos: estudiosos, curiosos. Portanto, se o quiséssemos caracterizar diríamos que este é um público letrado, um público que lê, que para a época em análise, e no caso de Portugal, é uma minoria.

A Biblioteca assegurou desde início um serviço de leitura pública, que passou a ser objeto de registo em livro próprio, a partir de 1875 e, a partir de 1887, os dados referentes ao movimento de leitores e visitantes passaram também a constar no Anuário Estatístico de Portugal. É sobre a leitura pública e recorrendo sobretudo a essas fontes que incide este nosso trabalho.

Os problemas para fazer a História de Leitura têm sido referidos pela historiografia, que desde início a considerou uma nova forma de fazer história (Darton, 2003, p. 189) a exigir por parte do historiador atenção especial às fontes, sejam elas os registos em diários e a correspondência (Brewer, 1997, p. 159), sejam sobretudo os relatórios de bibliotecários e verbetes de leitura das bibliotecas públicas ou particulares. Muitas são as possibilidades de fazer a história da leitura, como bem documentam os trabalhos de Albert Manguel (1998), e nas palavras de Christine Pawley (2009) a leitura é um hábito com história.

Em Portugal, e relativamente ao período que tratamos, José Tengarrinha analisou a leitura pública, durante os últimos 28 anos da monarquia (1883-1910), apresentando dados quantitativos sobre o movimento de leitores em 11 bibliotecas públicas. Importa reter o lugar ocupado por Évora, com um total de 30.724 leitores (1883-1910), 1,6\% do total nacional. Com mais leitores surgem Lisboa (Biblioteca Nacional e bibliotecas municipais), Coimbra, Porto, Santarém e Ponta Delgada (Tengarrinha, 1984, p. 203). Também Fernando Gameiro apresenta dados para o mesmo período, indicando a evolução anual de leitores. Numa perspetiva de associação da leitura com a educação e o lazer, apresenta-nos as preferências de leitura e as atividades profissionais dos leitores em cinco anos: 1875, 1880, 1885, 1897 e 1900. Os dados que recolheu nos livros de registo de leitores comprovam o predomínio da leitura de obras literárias e históricas, por um público maioritariamente constituído por estudantes (Gameiro, 1997, p. 162).

Este trabalho retoma estes estudos, ampliando a dimensão temporal de modo a integrar as mudanças e continuidades que o novo regime republicano trouxe para a leitura pública. Partimos também com um dado que os estudos anteriores omitiram que é o facto da Biblioteca de Évora ter neste período a seu cargo uma importante coleção museológica e por isso ter também assegurado o serviço de museu. Por isso, a par dos leitores a biblioteca recebia diariamente visitantes, das mais variadas proveniências e que normalmente eram fator de perturbação para os leitores.

O objetivo central do trabalho é caracterizar o afluxo de leitores e visitantes, entre 1887-1921, de modo a traçar o perfil de leitor que frequentava a biblioteca pública na transição do século XIX para o século XX. Deste modo, procuramos também compreender a função social da biblioteca pública, num contexto social e económico em que a iliteracia era a característica dominante, em que os recursos biblioteconómicos são escassos e que os leitores continuam a ser uma minoria.

Como fontes para a nossa análise, recorremos aos relatórios de bibliotecários com indicação numérica do movimento de leitores, a partir de 1841, embora de forma pouco sistemática. Dados mais fidedignos, nomeadamente os livros de registo dos leitores, livros de registo de visitantes e verbetes de leitura, só começaram a ser uma realidade a partir de 1864. Estas fontes encontram-se no Arquivo Distrital de Évora e é este fundo e os dados publicados sistematicamente pelo Anuário Estatístico de Portugal que utilizamos nesta abordagem. Começamos por dar uma evolução da coleção, que estava disponível para os leitores e também para os visitantes que desde muito cedo demandavam a instituição. 


\section{A COLEÇÃO}

Os leitores tiveram nos primeiros anos à sua disposição uma coleção bibliográfica rica e atualizada, proveniente dos donativos feitos por D. Manuel do Cenáculo e do anterior arcebispo de Évora, D. Joaquim Xavier Botelho de Lima. Além dos livros, o espólio da biblioteca incluía uma coleção museológica apreciável, constituída por antiguidades, nome que então designava as peças arqueológicas, pinturas, um monetário e uma coleção de produtos naturais; animais embalsamados, conchas, herbário e outros espécimes do género.

Não é tarefa fácil dar uma evolução quantitativa das coleções da Biblioteca Publica, dada a falta de um catálogo sistemático. No ano em D. Manuel do Cenáculo morreu, em 1814, o juiz do inventário post mortem, José António de Leão, avaliou a coleção de livros e manuscritos em 50.000 volumes (Vaz, 2006, p. 67). Mas a Biblioteca sofrera já grandes perdas, em 1808, provocadas pela ocupação e saque do exército francês e posteriormente durante o período liberal e guerra civil essas perdas continuaram (Vaz, 2006, p. 64).

A atualização da coleção esteve no início dependente da filantropia de bibliófilos locais, que doaram obras e mesmo dinheiro à biblioteca. Assim, o bibliófilo eborense António Baptista Sequeira Faca-Mello, em 1824, doou à Biblioteca de Évora a sua livraria, que se compunha de aproximadamente 1.500 volumes e um fundo de 600.000 réis para com os juros ir pagando os ordenados dos funcionários. Seguiram-se outros, nomeadamente, o Bacharel da Sé, Joaquim Cordeiro, que deixou parte da sua coleção bibliográfica a Biblioteca Pública (Vaz, 2007, p. 8).

A coleção foi enriquecida durante os anos em que o bibliotecário Cunha Rivara dirigiu a biblioteca, quando se procedeu à integração dos fundos conventuais e à compra de obras recentes, recorrendo à venda de obras dobradas. Nos anos seguintes, já no final da década 1880, a biblioteca passou a receber com regularidade obras recentes, enviadas pela Inspeção Geral das Bibliotecas e Arquivos Públicos, criada pelo decreto de 29 de Dezembro de 1887. O relatório enviado a Inspeção, em 1899, dá-nos um quadro completo das coleções da biblioteca.

\begin{tabular}{|l|l|}
\hline Categorias & Volumes/ Espécimes \\
\hline Obras impressas & 43724 \\
\hline Manuscritos & 2858 \\
\hline Cartas Geográficas & 526 \\
\hline Estampas & 314 \\
\hline $\begin{array}{l}\text { Partitura/obras } \\
\text { música }\end{array}$ & 346 \\
\hline Retratos & 516 \\
\hline Numismática & 5312 \\
\hline TOTAL & $\mathbf{5 3 5 9 6}$ \\
\hline
\end{tabular}

Tabela I. A Coleção da Biblioteca Pública de Évora em 1899. (Fonte: ADE - F BPE: SC. E; SR 01- 1895-1902, np).

O referido relatório, como se constata, inclui livros impressos e manuscritos, estampas, retratos e numismática (moedas, medalhas e selos pendentes), mas não inclui outros dados da coleção museológica, que continuava na dependência da biblioteca, os produtos naturais que vinham do tempo do arcebispo Cenáculo. Coleção que continuou na dependência da instituição até 1915 , ano em que foi criado o Museu de Évora ${ }^{3}$.

Nesse mesmo ano de 1899, a biblioteca recebeu da Inspeção das Bibliotecas, além dos livros, moedas e medalhas para enriquecer o seu monetário, como deixou escrito o Conservador da Biblioteca, José Maria Queiroz Veloso:

Recebi todas as obras que constam da lista supra. Igualmente recebi do Senhor Tesoureiro da Inspeção Geral das Bibliotecas e Arquivos Públicos um pacote com 16 moedas em prata, além das moedas e medalha comemorativas do centenário da Índia em número de $12^{4}$.

Outras incorporações ocorreram por motivo da extinção das casas religiosas femininas. Em resultado das disposições legais, a Biblioteca de Évora beneficiou a integração das coleções bibliográficas e artísticas desses estabelecimentos. Em 1899 a biblioteca e museu recebiam os objetos e obras de arte pertencentes ao Convento do Paraíso, nomeadamente, um brasão de armas reais da primeira dinastia, capitel, carranca e um quadro de azulejos representando Santo António 5 . 
Mais significativa foi a integração nas coleções dos objetos e património artístico e bibliográfico, do Convento de Santa Clara, em 1903. O termo de entrega dos livros e objetos que pertenciam ao extinto convento de Santa Clara, datado de 17-10-1903 é assinado pelo Diretor da Biblioteca Pública, António Joaquim Lopes da Silva e pelo Delegado do Tesouro. O documento discrimina em duas relações os objetos destinados ao museu e os livros destinados à biblioteca, indicando a avaliação para cada espécimen. Os objetos que foram entregues ao Museu da Biblioteca Pública de Évora foram avaliados em 51.160 réis e incluem, entre outros: um resplendor de prata (5.260), cadeiras, sinete, um tapete de Arraiolos (avaliado em 15.000 réis, o mais alto valor), um frontal de seda branca bordada (10.000), uma mesa pequena de pau-santo (2.000) e uma pintura a óleo representando S. Francisco (400 réis) ${ }^{6}$.

A relação dos livros que pertenciam ao suprimido Convento de Santa Clara de Évora, com indicação do número de inventário, título e avaliação, enumera 95 obras, avaliadas em 28.500 réis. Entre os que foram considerados mais valiosos, encontram-se 33 volumes do breviário romano (2.000 réis), 36 breviários (2.600), um breviário datado de 1697 (1.400), um livro para missa de cantochão (2.500), um antifonário seráfico, (1.000), um grande livro em cantochão (1.500). Além destes a lista inclui livros de horas e oito volumes da Crónica de S. Francisco (avaliados em 800 réis). Refira-se que a relação inclui também obras manuscritas, onde avultam sete maços de pergaminhos, que não foram avaliados ${ }^{7}$.

De acordo com o Anuário Estatístico de Portugal no ano de 1905, a Biblioteca tinha uma coleção bibliográfica de 45.754 volumes $^{8}$; e em 1921 esse número subiu para 53.916 volumes ${ }^{9}$. Dados que comprovam uma razoável atualização da coleção, em grande parte fruto do envio de obras pela Secretaria da Inspeção das Bibliotecas e Arquivos e das incorporações de obras já referidas.

Comparada com outras bibliotecas públicas, a Biblioteca de Évora tinha neste período uma das mais ricas e volumosas coleções, só superada pela Biblioteca Nacional, a Biblioteca Pública do Porto, a Biblioteca da Universidade de Coimbra e a Biblioteca da Academia das Ciências de Lisboa. As bibliotecas existentes em cidades da província, a exceção da Biblioteca Pública de Braga, estavam muito longe de poder ombrear com a de Évora e, de um modo geral, tinham pequenas coleções, entre os 1.000 e 5.000 volumes. De acordo com o Anuário em 1905 a Biblioteca de Évora era a que, entre as bibliotecas de província tinha a coleção mais volumosa (45.754 volumes). O número de volumes apontados para as bibliotecas das capitais de distrito nas províncias e para esse ano são os seguintes, por ordem crescente: Guarda (2.311), Santarém (3.157), Castelo Branco (3.268), Beja (4.038), Angra do Heroísmo (5.674); Elvas (14.040); Ponta Delgada (18.515) e Braga $(38.778)^{10}$.

À semelhança do que acontecia na Biblioteca Nacional também em Évora, além da leitura presencial, os leitores e investigadores podiam solicitar a cópia de textos e mesmo a fotografia de manuscritos e reservados, através de requerimento escrito dirigido à Inspeção das Bibliotecas e Arquivos. Foi também por ação desta mesma instituição que a Biblioteca beneficiou, a partir de início do seculo XX, de um serviço de permutação internacional. Encontramos referências a permutas de obras sobretudo com a Biblioteca Nacional de Lisboa e, a nível internacional, com a Biblioteca Nacional do Rio de Janeiro ${ }^{11}$.

Tudo leva a crer que o empréstimo domiciliário não era uma prática corrente e só excecionalmente podia ser concedido pela Inspeção das Bibliotecas. De acordo com as normas em vigor, o próprio bibliotecário estava sujeito a este carácter excecional, como comprova uma lista que o bibliotecário José Maria Queiroz Veloso apresentou, em 1899, com os livros impressos e manuscritos que tinha em seu poder para fazer a História da Universidade de Évora. Diz o referido bibliotecário, nessa lista por ele assinada, que se obriga a entregá-los logo que lhe fosse exigido e «tomando inteira e absoluta responsabilidade por qualquer falta, extravio ou deterioração que em qualquer desses livros ou manuscritos possa haver» ${ }^{12}$.

Com o decreto de 29 de Janeiro de 1903 passou a vigorar uma rigorosa fiscalização dos empréstimos domiciliários, para a Biblioteca Nacional e restantes bibliotecas públicas. O prazo estipulado para o empréstimo era um mês, mas excluindo obras raras, manuscritos e obras com um único exemplar. Também era expressamente proibido o empréstimo de cartas, estampas e moedas. O referido decreto determinava ainda uma caução a deixar pelo leitor e arbitrada pelo diretor da biblioteca ${ }^{13}$.

A propósito do empréstimo, encontramos uma circular do inspetor da Secretaria das Bibliotecas e Arquivos Nacionais, enviada à Biblioteca Pública de Évora em 1909. Nela se dá conta da inspeção feita na Biblioteca Nacional, pela qual se constatou que o serviço de empréstimo não estava a ser executados «em condições regulares de segurança e integridade das respetivas coleções» ${ }^{14}$. $\mathrm{Na}$ circular apontam-se alguns dos abusos cometidos, nomeadamente, o facto de alguns leitores pedirem livros para depois os vender. O inspetor recomenda que se reclame, 
por carta registada dirigida aos detentores, os livros emprestados há mais de dois meses, dando prazo de 15 dias para os restituir.

Interessa também nesta circular reter a ideia que no início do século se tinha relativamente às novidades e ao serviço de empréstimo. O inspetor conclui que não se podem aplicar às bibliotecas eruditas e arquivos as mesmas normas e doutrinas que se aplicam nas bibliotecas públicas e livres do estrangeiro, considerando que estas instituições «têm como principal objetivo não a conservação do livro mas a sua dispersão» ${ }^{15}$. Por isso, para as bibliotecas públicas portuguesas recomenda o rigoroso cumprimento das normas estipuladas pelo decreto de 29 de Janeiro de 1903 e relativas ao empréstimo de livros e também a rigorosa escrituração dos empréstimos, proibindo o empréstimo de livros de que haja só um exemplar, de livros raros ou de carácter reservado, de coleções de jornais e de manuscritos, moedas e estampas e a proibição do empréstimo de mais de cinco volumes à mesma pessoa.

A ideia que está subjacente é que mais do que a leitura pública, as bibliotecas deveriam ter como primeira prioridade a conservação dos livros. Por isso, não é de admirar que no caso de Évora o Diretor do Estabelecimento tenha também o título de Conservador.

Feita esta caracterização da coleção disponível passemos a movimento de leitura e à sua evolução.

\section{A LEITURA PÚBLICA NA TRANSIÇÃO DO SÉCULO XIX PARA O SÉCULO XX}

Dada a falta de dados estatísticos sistemáticos antes de 1864, resta-nos as avaliações qualitativas. Assim durante o período inicial, e de acordo Augusto Simões, a biblioteca tinha uma boa afluência de "mestres e estudantes". Parece ser uma preocupação dos primeiros bibliotecários assegurar o cumprimento do serviço público como determinado nos Estatutos e tratar bem os leitores que demandava a instituição ${ }^{16}$.

A biblioteca nos primeiros anos da sua existência dependia da Mitra episcopal e os seus principais responsáveis e financiadores eram os arcebispos, primeiro o fundador, D. Manuel do Cenáculo, depois os sucessores. Era, portanto, uma instituição vinculada à Igreja e dela dependente. Competia ao arcebispo nomear os funcionários, ou como então se dizia os oficiais, assegurar com a dotação prevista de 500.000 réis o seu funcionamento.

A abertura ao público leitor, que os Estatutos da Biblioteca de Évora consagraram em 1811, além de ser ainda muito restrita ${ }^{17}$, teve no caso da instituição uma conjuntura adversa, que dificultou a leitura pública. Mas as dificuldades não provieram apenas da conjuntura política adversa e das dificuldades económicas inerentes, mas também da própria vontade dos homens. Com efeito, logo após a morte de D. Manuel do Cenáculo os sucessores questionaram a manutenção deste serviço público, invocando as dificuldades financeiras que acarretava (Vaz, 2006, p. 78). Tudo leva a crer que até 1887 a frequência da biblioteca pelo público foi incipiente.

Com a publicação do Anuário Estatístico de Portugal, a partir de 1887, passámos a ter dados relativos ao movimento de leitores e visitantes. Desde a fundação, como referimos, a biblioteca reunia a coleção museológica, onde se incluíam as antiguidades arqueológicas, pinturas, a colecção de produtos naturais, monetário e outros bens culturais coligidos pelo fundador. Portanto, desde o início tinha um público de visitantes, que muitas vezes contribuíam para o desassossego dos leitores, como testemunhou o bibliotecário Augusto Filipe Simões.

Estou convencido de que a biblioteca seria muito mais procurada e frequentada, se oferecesse aos leitores o sossego e a comodidade, que hoje não encontram, e, que não raras vezes, vêm ainda os visitantes perturbar a ordem e o silêncio, que deveriam aqui mesmo reinar. Além disso não há para os leitores senão duas mesas e uns mochos de pinho pintado, cuja vista basta para afugentar da biblioteca aqueles que desejam passar algumas horas a ler ${ }^{18}$.

Façamos aqui um parêntesis para analisar um pouco melhor esse afluxo de visitantes, que no entender de Filipe Simões constituíam um obstáculo para um serviço público eficiente. Desde muito cedo que a biblioteca contou com a curiosidade do público, atraído pelas valiosas coleções e também para apreciar a magnifica sala de leitura. A biblioteca está situada no centro histórico da cidade, bem próximo do templo de Diana, e é considerada uma das mais belas de Portugal (Silva, 2013, p. 161); é portanto natural que, desde a sua fundação, tenha despertado o interesse e curiosidade dos viajantes.

Em 1806, o Príncipe Regente e restante família real visitaram a biblioteca; mas seria na segunda metade do século XIX que o fluxo de visitantes se incentivou. Foi certamente esse afluxo que motivou o aparecimento de um registo sistemático em livro próprio. A partir de 1860 e até 1967 dispomos de um conjunto de livros exclusivamente para esse 
fim - mais propriamente sete livros, sendo o primeiro intitulado: Assignaturas de todas as pessoas que vizitaram esta Bibliotheca, Évora 22 de Dezembro de 1860 até $1870 .{ }^{19}$ Estes livros enumeram visitantes de acordo com um modelo, em três colunas, em que se anota o nome do visitante, a naturalidade e a data da visita ${ }^{20}$.

Com base neste fundo, e sem querermos aqui fazer um tratamento estatístico ${ }^{21}$, é possível comprovar uma boa e constante afluência de público curioso, provavelmente não apenas sobre os livros, mas sobre todo o espólio da biblioteca. Público que nos ajuda a compreender melhor a ideia de biblioteca, como representação. Ou seja, é significativo que desde o século XIX uns bons milhares de curiosos tenham visitado a instituição com o intuito de ver os seus tesouros bibliográficos, revelando interesse pelos livros, pela sua disposição e, provavelmente alguns, teriam interesse pela leitura. Contemplar os livros é já um princípio de motivação para a leitura de predisposição para a bibliofilia. Mas, e para darmos razão a Augusto Simões, um público de visitantes ruidosos e dando asas ao seu espanto, não é certamente propício ao recato que implica uma sala de leitura. Por outro lado, e voltando a representações, mais do que ler este público quer ver e se possível tocar nos livros, prolongando assim uma mentalidade ou atitude barroca: o público está na biblioteca, mas não tanto para ler mas para abrir a boca de espanto.

Mas quantos leitores frequentavam a biblioteca? Quais as suas leituras? E qual a relação entre este público leitor e os níveis de literacia? Para responder a estas questões temos os dados publicados no Anuário Estatístico que, ainda que com alguns lacunas, indicam o número de leitores e volumes requisitados, bem como o número de visitantes da biblioteca-museu e a partir de 1904 o número de jornais e revistas requisitadas. A tabela seguinte resume o serviço público da biblioteca ${ }^{22}$.

\begin{tabular}{|l|l|l|l|l|l|}
\hline ANO & LEITORES & $\begin{array}{c}\text { TOTAL } \\
\text { vol. }\end{array}$ & VISITANTES & $\begin{array}{c}\text { LEITORES } \\
\text { de jornais }\end{array}$ & VOLUMES \\
\hline $1887-1890$ & 2.637 & 2.625 & 2.002 & - & - \\
\hline $1891-1894$ & 3.671 & 3.685 & 2.800 & - & - \\
\hline $1895-1898$ & 3.835 & 3.959 & 2.212 & - & - \\
\hline $1899-1902$ & 4.492 & 5.991 & 2.352 & - & - \\
\hline $1903-1906$ & 6.362 & 6.587 & 2.282 & 782 & 816 \\
\hline $1907-1910$ & 9.727 & 10.675 & 1.900 & 2.871 & 3.378 \\
\hline $1917-1921$ & 6.821 & 7.302 & 2.707 & 1.168 & 1.234 \\
\hline
\end{tabular}

Tabela II. Leitores e Visitantes da Biblioteca Pública de Évora (1887-1921). (Fonte: Anuário Estatístico de Portugal, 18871921, Tengarrinha, 1984, p. 199).

Durante estes 28 anos e relativamente à leitura de livros, temos uma média anual de 1.341 leitores e 1.458 livros requisitados, incluindo a leitura de jornais a partir de 1904. O número global de leitores foi aumentando paulatinamente, com alguns momentos de maior afluência, como os anos de 1908 a 1910, provavelmente por causa da conjuntura política que ficou marcada pelo regicídio, seguido da implantação da república. No mesmo sentido podemos interpretar a subida de leitores em 1918, ano em que termina a grande guerra. É natural que a afluência de leitores seja maior nestes tempos de guerra e instabilidade política, procurando a informação sobretudo nos jornais.

No contexto biblioteconómico nacional, relativamente à leitura pública, tomando como referência o ano de 1905 , a Biblioteca Pública de Évora, com 1.721 leitores, ocupava um honroso $7^{\circ}$ lugar, tendo à frente a Biblioteca Nacional (29.694), A Biblioteca Municipal do Porto (21.437), as Bibliotecas Municipais de Lisboa (8.261), a Biblioteca da Universidade de Coimbra (7.683), a Biblioteca Municipal de Angra do Heró́smo (2.861) e a Biblioteca Municipal de Ponta Delgada (1.853). Estava à frente de bibliotecas de cidades de província com mais população como as de Santarém e Braga. A Biblioteca de Évora representava nesse ano 2,6\% do total de leitores, a nível nacional (Tengarrinha, 1984, p. 203).

Para saber o que liam, ou seja, quais os temas mais procurados, temos a distribuição que os bibliotecários nos deixaram, relativamente aos livros requisitados. Todavia, de 1887 a 1900 a organização ou divisão por temas refere apenas três categorias: História e Literatura, Ciências e Artes e Manuscritos. 


\begin{tabular}{|r|c|c|c|r|r|r|r|r|}
\hline ANO & Leitores & $\begin{array}{c}\text { TOTAL } \\
\text { (vols.) }\end{array}$ & $\begin{array}{c}\text { e História } \\
\text { Literatura }\end{array}$ & \multicolumn{1}{c|}{$\begin{array}{c}\text { Ciências } \\
\text { e Artes }\end{array}$} & $\mathbf{\%}$ & Manuscritos & \% \\
\hline $\mathbf{1 8 8 7}$ & 950 & 1.033 & 1003 & 97 & 20 & 2 & 10 & 1 \\
\hline $\mathbf{1 8 8 8}$ & 757 & 646 & 630 & 98 & 12 & 2 & 4 & 1 \\
\hline $\mathbf{1 8 8 9}$ & 773 & 786 & 770 & 98 & 10 & 1 & 6 & 1 \\
\hline $\mathbf{1 8 9 0}$ & 157 & 160 & 144 & 90 & 10 & 6 & 6 & 4 \\
\hline $\mathbf{1 8 9 1}$ & 559 & 559 & 509 & 91 & 30 & 5 & 20 & 4 \\
\hline $\mathbf{1 8 9 2}$ & 619 & 617 & 547 & 89 & 44 & 7 & 26 & 4 \\
\hline $\mathbf{1 8 9 3}$ & 1.249 & 1.257 & 1.025 & 82 & 60 & 5 & 172 & 13 \\
\hline $\mathbf{1 8 9 4}$ & 1.244 & 1.252 & 1.072 & 86 & 30 & 2 & 150 & 12 \\
\hline $\mathbf{1 8 9 5}$ & 970 & 985 & 845 & 86 & 68 & 7 & 72 & 7 \\
\hline $\mathbf{1 8 9 6}$ & 869 & 876 & 723 & 83 & 38 & 4 & 115 & 13 \\
\hline $\mathbf{1 8 9 7}$ & 938 & 950 & 670 & 71 & 184 & 19 & 96 & 10 \\
\hline $\mathbf{1 8 9 8}$ & 1.058 & 1.148 & 867 & 76 & 134 & 12 & 147 & 12 \\
\hline $\mathbf{1 8 9 9}$ & 1.186 & 2.154 & 1.987 & 92 & 98 & 5 & 69 & 3 \\
\hline $\mathbf{1 9 0 0}$ & 930 & 1.432 & 1.218 & 85 & 108 & 8 & 106 & 7 \\
\hline
\end{tabular}

Tabela III. Leitores por temática (1887-1900). Fonte: Anuário Estatístico de Portugal, 1887-1900.

Como a tabela documenta, os livros mais procurados eram os de Literatura e História. Quando consultámos os dados para os restantes anos, até 1917 notamos a mesma tendência, embora os bibliotecários façam agora uma maior discriminação dos livros requisitados em 12 categorias: História e Geografia, Belas Letras, Ciências Exatas, Ciências Naturais, Indústria, Belas Artes, Filosofia, Ciências Teológicas, Bibliografia, jornais e manuscritos. Não se percebe muito bem a distinção feita entre Literatura e Belas-letras, uma vez que esta inclui por norma e já nessa época, a gramática, poesia e literatura.

A partir de 1917, o número de categorias é reduzido de forma mais racional a 6: História e Geografia, Comércio e Indústria, Literatura e Belas Letras, Artes e Ciências, Jornais e Revistas, Manuscritos e diversos. Tomando como exemplo o período de 1917- 1919, a distribuição dos leitores e leituras é indicada na tabela seguinte.

\begin{tabular}{|c|c|c|c|c|c|c|c|c|c|c|c|c|c|c|}
\hline \multirow[t]{2}{*}{ Anos } & \multicolumn{2}{|l|}{ Total } & \multicolumn{2}{|c|}{$\begin{array}{cc}\text { Artes } & \mathrm{e} \\
\text { Ciências } & \end{array}$} & \multicolumn{2}{|c|}{$\begin{array}{l}\text { Comércio } \\
\text { Indústria }\end{array}$} & \multicolumn{2}{|c|}{$\begin{array}{l}\text { Historia } \\
\text { Geografia }\end{array}$} & \multicolumn{2}{|c|}{$\begin{array}{l}\text { Literatura } \\
\text { Belas Letras }\end{array}$} & \multicolumn{2}{|c|}{$\begin{array}{l}\text { Jornais e } \\
\text { Revistas }\end{array}$} & \multicolumn{2}{|c|}{$\begin{array}{l}\text { Manuscrito } \\
\text { s e diversos }\end{array}$} \\
\hline & L. & V. & L. & V. & L. & V. & $\mathbf{L}$ & V. & L. & V. & L. & V. & L. & V. \\
\hline 1917 & 1.622 & 1.835 & 26 & 55 & 0 & 0 & 48 & 60 & 35 & 1.370 & 311 & 345 & 2 & 5 \\
\hline 1918 & 2.010 & 2.102 & 242 & 265 & 0 & 0 & 92 & 94 & 1.244 & 1.280 & 401 & 425 & 31 & 38 \\
\hline 1919 & 1.536 & 1.635 & 57 & 75 & 0 & 0 & 69 & 75 & 1.045 & 1.115 & 357 & 360 & 8 & 10 \\
\hline
\end{tabular}

Tabela IV. Leitores por temática (1917-1919). Fonte: Anuário Estatístico, 1917-1919. L. Livros; V. Volumes.

A Literatura é de longe a temática mais procurada, representando em média nos três anos $68 \%$ dos livros requisitados; seguem-se os jornais e revistas, com 20\%, as Artes e Ciência, 7\%; História e Geografia, com 4\% e os manuscritos com $1 \%$. 
As temáticas escolhidas pelos leitores ao longo do período, com um domínio avassalador da literatura e a história, comprovam uma leitura de fruição, de passatempo embora não seja de excluir que a leitura de obras de autores portugueses ou mesmo estrangeiros, não seja também feita por motivos académicos ou de documentação. É também de referir uma procura significativa de textos manuscritos- em alguns anos acima de $10 \%$ de leitores - o que tem a ver certamente com pesquisa de eruditos para redação de obras de cariz histórico, particularmente de genealogia.

Quanto aos estratos sociais a que os leitores pertenciam, podemos comprovar que persistia um público maioritariamente constituído por estudantes do liceu, continuando a tradição que vinha de meados do século XIX. Dado que convém também anotar é a percentagem de leitores de jornais, que foi sempre aumentando o que demonstra o interesse do público pelo carácter noticioso da imprensa periódica.

Relativamente à relação da leitura pública com os níveis de literacia da população, importa recorrer aos censos realizados neste período. O primeiro dado a referir, e que é sobejamente referenciado na historiográfica como dado estruturante no país, é o elevado nível de iliteracia da população em geral. Assim, de acordo com os dados do Anuário Estatístico o país tinha em 1878 uma das mais altas taxas de analfabetismo da Europa, 82, 4\% dos portugueses não sabia ler nem escrever, e dos 17,6\% alfabetizados, é preciso ainda referir que havia ainda 3, $21 \%$ que só sabiam ler e apenas 14,3\% sabia ler e escrever (Carvalho, 1981, p. 614).

O distrito de Évora integra-se neste contexto e, como distrito predominantemente rural, apresentava números de iliteracia mais elevados, que a média nacional e cuja evolução consta da tabela seguinte.

\begin{tabular}{|c|c|c|c|c|c|c|}
\hline \multirow{2}{*}{ ANO } & $\begin{array}{c}\text { POP. } \\
\text { CIDADE DE } \\
\text { ÉVORA }\end{array}$ & $\begin{array}{c}\text { POP. } \\
\text { DISTRITO } \\
\text { DE ÉVORA }\end{array}$ & \multicolumn{2}{|c|}{$\begin{array}{c}\text { Alfabetizados- } \\
\text { Distrito }\end{array}$} & \multicolumn{2}{|c|}{$\begin{array}{c}\text { Analfabetos- } \\
\text { Distrito }\end{array}$} \\
\cline { 4 - 7 } & & & $\mathbf{N}^{\mathbf{0}}$ & $\mathbf{\%}$ & $\mathbf{N}^{\mathbf{0}}$ & $\mathbf{\%}$ \\
\hline 1878 & 13.046 & 106.858 & 17.037 & 15,9 & 89.821 & 84,1 \\
\hline 1890 & 15.134 & 118.408 & 22.049 & 18,6 & 96.359 & 81,4 \\
\hline 1900 & 16.152 & 128.062 & 22.661 & 17,7 & 105.401 & 82,3 \\
\hline 1911 & 17.911 & 150.020 & 31.015 & 20,7 & 119.005 & 79,3 \\
\hline 1920 & 18.615 & 155.918 & 35.128 & 22,2 & 120.790 & 77,8 \\
\hline
\end{tabular}

Tabela V. Evolução da Literacia no distrito de Évora. Fonte: Anuário Estatístico, 1884- 1921.

Perante os dados, e com tais níveis de iliteracia, é bom de ver que a leitura pública era um luxo de uma minoria e que a biblioteca só podia ser frequentada por essa minoria, que em termos percentuais rondava os $20 \%$ da população do distrito. Mas mesmo entre os alfabetizados, nem todos tinham possibilidade de frequentar a biblioteca, quer por razões profissionais, que impediam muitos de usufruir da leitura mesmo residindo na cidade, quer porque viviam no meio rural, e ir a biblioteca significava uma deslocação cara, dadas as dificuldades de transporte. Por isso, a biblioteca estava ao serviço maioritariamente dos leitores citadinos, com disponibilidade de tempo, e dos viajantes que a visitavam para ver as suas coleções. Estes condicionalismos reforçam a nosso ver a leitura de fruição e a leitura de complemento dos ensinamentos dos professores, neste caso para estudantes do liceu.

É também esta a constatação que retiramos da consulta dos Livros de Requisição de Leitura que a partir de 1869 registam a profissão dos leitores ${ }^{24}$. O registo sistemático de movimento de leitores é feito em livros que vão variando de modelo. Assim, entre 1869-1899, registava-se o dia, nome do leitor, os títulos das obras lidas e as temáticas das obras que se dividiam em sete categorias: Históricas e Literárias, Ciências (Eclesiásticas, Morais, Naturais, Artes e Ofícios), Belas Artes, Jornais Literários e Políticos, e Manuscritos. Indicava-se também o total de leitores e de obras. A partir de 1899 o registo passou a ser mais simples, indicando em quatro colunas: o dia, o nome do leitor, a profissão e o título das obras consultadas ${ }^{25}$. Uma análise qualitativa a estes livros permite deduzir que a biblioteca tinha uma frequência de cerca de 5 leitores por dia, que eram sobretudo estudantes, incluindo os seminaristas (que aparecem também mencionados), militares, negociantes, funcionários públicos e proprietários ${ }^{26}$.

\section{OS BIBLIOTECÁRIOS}

Ontem como hoje o papel dos bibliotecários ou responsáveis pela biblioteca é um fator que devemos ter em conta nas análises ao movimento de leitura pública. A lista completa dos Bibliotecários, desde a sua fundação até 1950, foi apresentada por Túlio Espanca (Espanca, 1982, p. 203). No início como a instituição dependia da Mitra, os bibliotecários eram eclesiásticos e nomeados pelo arcebispo da cidade. Da sua obra falamos em anterior trabalho, que teve de enfrentar tempos marcados pela guerra e situação económica adversa (Vaz, 2006, p. 64). 
A partir de 1838 a instituição entrou numa nova era com a nomeação do primeiro bibliotecário civil, Joaquim Heliodoro da Cunha Rivara, bacharel em Medicina e Professor de Filosofia no Liceu de Évora. Durante os dezassete anos, que esteve a frente e como diz Augusto Simões, «trabalhou sempre com incansável zelo na conservação e aumento da biblioteca ${ }^{27}$. Entre os trabalhos que desenvolveu, destaca-se o inventário e arrumação dos numerosos manuscritos, principiando o Catálogo dos Manuscritos. Foi também Cunha Rivara que iniciou a integração dos livros impressos provenientes das livrarias dos extintos conventos masculinos na biblioteca ${ }^{28}$.

Os relatórios feitos por Cunha Rivara, ao todo cinco, são uma fonte importante para compreendermos a sua acção de bibliotecário ${ }^{29}$. O primeiro relatório data de 1845 e foi analisado por Pedro Cérico, que o considerou o mais pormenorizado (Cerico, 2007, p. 230). Neste relatório, Rivara faz um inventário das necessidades da casa apontando cinco itens: o primeiro e o segundo referem-se aos fundos bibliográficos, considerando urgente para garantir a afluência do público a compra de obras modernas, e que nesse sentido se possa despender a quantia anual de 150.000 réis. O terceiro refere-se a necessidade de aumentar o espaço, para acolher os fundos dos conventos, sugerindo a construção de mais salas nos terrenos dos Loios. O quarto, a contratação de um escriturário para ajudar o Bibliotecário na arrumação dos livros, continuação dos catálogos e a trasladação de manuscritos deteriorados. No último item considera que se deve autorizar o Governo Civil e o Bibliotecário a venderem «os livros dobrados», para arranjar fundos para comprar obras modernas.

Este enunciado além de confirmar a atualização bibliográfica da colecção, demonstra também que a biblioteca como espaço público não constituía uma preocupação relevante para o Cunha Rivara. Aliás a este propósito, em resposta a circular do Ministério do Reino de 1849, o panorama que dá sobre a frequência de leitores é desolador: A pergunta da circular: "quantos leitores, termo médio, frequentam diariamente a biblioteca"? A resposta de Rivara é a seguinte: "Termo médio dos leitores - 3 a quatro por dia" (Cerico, 2007, p. 234).

Mas também relativamente à conservação, ou porque não houve continuidade nas medidas tomadas por Cunha Rivara, ou porque elas eram pouco consistentes, o balanço acaba por ficar muito aquém do esperado. De facto, o bibliotecário Augusto Filipe Simões, que iniciou o seu cargo em 1865, descreveu no relatório de 1868 um quadro negro sobre a situação da Biblioteca. A sala nova, feita há pouco mais de 15 anos, ameaçava ruir e os fundos bibliográficos, mesmo os mais valiosos, estavam mal acondicionados e a deteriorar-se. Filipe Simões cita o exemplo de algumas preciosidades, um exemplar do primeiro livro impresso, a celebre Bíblia de Gutenberg e a obra Vita Cristhi - primeiro livro impresso em Portugal. Estas obras estavam, juntamente com o resto da coleção de incunábulos, cobertos de bolor num gabinete escuro e muito húmido ${ }^{30}$. E se a obra Vita Christi consta do Catálogo de incunábulos da Biblioteca Pública e Arquivo Distrital de Évora (Cid, 1988, p. 38), já a Bíblia de Gutenberg desapareceu.

Outro aspeto que se iniciou com Cunha Rivara e que nos parece ter influenciado negativamente o serviço público, foi a acumulação do cargo de bibliotecário com o de professor do liceu. Esta prática continuou com os sucessores de Cunha Rivara até meados do século XX, em que muitos dos bibliotecários foram também professores de liceu ${ }^{31}$. Dado ser uma prática comum em muitas bibliotecas do país, a própria Inspeção das Bibliotecas e Arquivos a reconheceu e sancionou, através de circular dirigida aos diretores das bibliotecas, datada de 12-3-1910, dando primazia ao serviço das aulas:

Como vários funcionários dos quadros das bibliotecas e arquivos nacionais se achem lecionando em liceus uns como professores efetivos, outros provisórios cumpre aos diretores das repartições atender para que os ditos funcionários conciliem o serviço das aulas, exercendo nos intervalos das mesmas as atribuições dos cargos para que foram nomeados, o que se participo a $V$. Ex $x^{a}$. para os devidos efeitos ${ }^{32}$.

Esta acumulação de cargos originava dificuldades no cumprimento dos horários das bibliotecas, dado que após a implantação da República a Inspeção Geral das Bibliotecas e Arquivos Nacionais enviou nova circular aos diretores das bibliotecas para que os funcionários das bibliotecas, que eram cumulativamente funcionários do liceu, consagrassem aos serviços bibliotecários e arquivísticos todo o tempo legal que os serviços liceais lhes deixassem livre ${ }^{33}$.

Este exercício simultâneo de funções não era salutar para as bibliotecas. De facto, se considerarmos que ser bibliotecário é um cargo útil e de maior importância para o progresso da educação no país teremos de admitir que deve ser exercido de pleno direito e a tempo integral. A biblioteca exige ao responsável máximo uma dedicação exclusiva e 
exige que as autoridades políticas assumam a importância e relevância desses serviços com o salário e estatuto competente.

A nível local o cargo era tido como relevante e como tal muito pretendido. Isso mesmo se deduz da correspondência que consultámos, onde figuram cartas dirigidas ao bibliotecário pelas autoridades civis e eclesiásticas locais, em especial do Governador Civil, do Presidente da Camara e do Arcebispo de Évora, reclamando a sua presença nos atos e cerimónias públicas, como tomadas de posse, procissões e missas solenes ${ }^{34}$.

A nível de preocupações com a leitura pública, e além do caso já mencionado de Augusto Simões, que nos seus relatórios apontou medidas para fomentar e dar novo rumo ao serviço público de leitura, são de referir algumas ações tendentes a renovação e atualização da coleção. António Lopes da Silva, em 1906, escreveu aos principais editores de Lisboa e Porto, solicitando o envio de obras "a título de ofertas". Responderam à solicitação a casa Ferreira e Oliveira de Lisboa e a Livraria Magalhães e Moniz, do Porto, a primeira enviou três obras, a segunda um catálogo para o diretor escolher as que a biblioteca não tinha, «e das quais nos lhe enviaremos as que podermos» ${ }^{35}$.

\section{CONCLUSÃO - PERFIL DE LEITOR}

No início do século XX, Portugal tinha uma rede escassa de bibliotecas públicas. Se excluirmos as bibliotecas populares $^{36}$, as bibliotecas de instituições de ensino e de associações diversas, a rede pública contava de acordo com o Anuário Estatístico de 1905 com 15 bibliotecas. Neste contexto os dados que coligimos comprovam que a Biblioteca de Évora era uma das principais bibliotecas nacionais, ocupava um honroso $5^{\circ}$ lugar em termos de coleção e tinha um movimento de leitores assinalável, representando $2,6 \%$ do total da leitura pública nacional.

Esbocemos o perfil de leitor da Biblioteca Pública de Évora na transição do século XIX para o seculo XX. Perante os dados do movimento de leitores e pelas temáticas de livros requisitados, sobressai um leitor que demanda a biblioteca em busca de passatempo ou para reforço dos ensinamentos colhidos no banco do liceu. Trata-se sobretudo de estudantes, eruditos locais, proprietários e um ou outro funcionário público, que de um modo geral leem livros de literatura e de história. A partir de 1904 este público de leitores reforça-se com os que procuram notícias e informação sobre o debate político, com a leitura de jornais. Excecionalmente um ou outro erudito, interessado pela história, consulta o acervo de manuscritos. Paralelamente, em concorrência com este público de leitores, e também diariamente, aparecem os visitantes curiosos e ruidosos para apreciar o que restava das coleções doadas por Frei Manuel do Cenáculo. Se acrescentarmos o quadro do mobiliário descrito por Augusto Simões, como sendo muito espartano, a biblioteca não era propriamente um local confortável e aprazível para a leitura.

A biblioteca, embora geograficamente no centro da cidade, estava muito longe da grande maioria dos habitantes persistindo numa representação de espaço destinado a uma minoria. Contra esta ideia remaram alguns dos bibliotecários que nos seus relatórios denunciaram as deficiências da biblioteca, quer a nível das condições do serviço público quer da conservação das coleções, e introduziram as novidades deste período, nomeadamente, a leitura de jornais que se revelou polo de atração para mais leitores. Mas as principais inovações foram fruto da administração central, que a partir de 1887 passou a controlar as instituições biblioteconómicas nacionais, através da Inspeção das Bibliotecas e Arquivos Nacionais, exigindo o cumprimento do registo estatístico da leitura pública e das coleções, possibilitando a permuta de obras entre a bibliotecas nacionais e estrangeiras, bem como a atualização das coleções, através do envio de obras recentes e supervisão da integração na Biblioteca Pública de Évora de novos fundos bibliográficos, das livrarias conventuais e doutras casas religiosas.

\section{NOTAS}

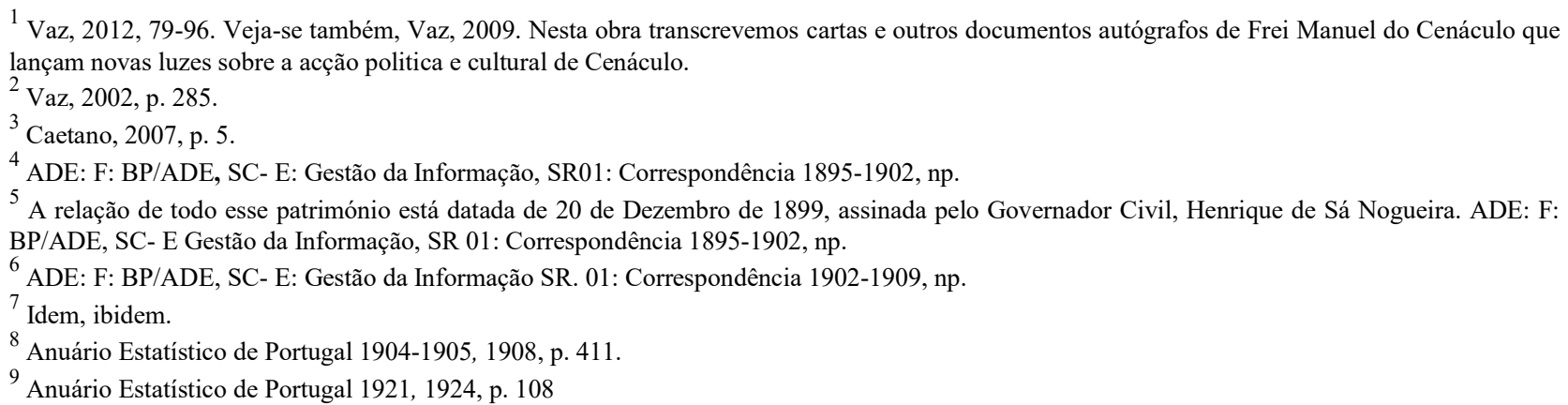


10 Anuário Estatístico de Portugal 1904-1905, 1908, p. 406-407. Esta situação de destaque vinha já de finais do seculo XIX. De acordo com os dados coligidos por Barata, 2003, p. 195-214, referentes ao ano de 1883; a Biblioteca da Guarda tinha uma coleção de 1.200 volumes, a de Beja, 1.523, a de Castelo Branco, 1.568, a do Funchal, 3200; a de Ponta Delgada: 5.127 e a Publica de Braga 25.134.

11 A primeira referência a este serviço que encontramos, datada de 2-7-1902, com envio de sete obras brasileiras à biblioteca de Évora. Este intercâmbio continua a bom ritmo, com a Biblioteca Nacional brasileira nos anos de 1902 a 1909. Cf. ADE: F: BP/ADE, SC-E: Gestão da Informação, SR.01: Correspondência 1902-1909, np.

${ }^{12}$ ADE: F: BP/ADE, SC- E: Gestão da Informação, SR 01: Correspondência 1895-1902, np.

13 Garcia e Martins, 1996, p. 220.

14 ADE: F: BP/ADE, SC- E: Gestão da Informação SR. 01: Correspondência 1902-1909, np.

15 Idem.

16 Mesmo a catalogação dos espécimes tinha como finalidade esse objetivo «era necessário extrair os livros com que estavam povoadas, e não menos colocá-los em outras estantes, e assinar-lhes seus lugares para não vedar o serviço público da Livraria, e antes satisfazer pontualmente os concorrentes com especialidade os estudantes que vinham instruir-se para as sabatinas, conclusões etc.». Simões, 1888 , p. 222.

${ }^{17} \mathrm{O}$ artigo oitavo determinava que quatro vezes por semana, nas manhãs de terça-feira e sábado e nas tardes de segunda e quinta, seria aberta para os concorrentes, que deviam ser tratados com « agrado e bom acolhimento, e franqueza», pelos oficiais e restantes empregados. Vaz, $2012 \mathrm{~B}$.

18 Espanca, 1981-1982, p. 245.

19 ADE: F: BP/ADE. Pública SC:I- Registo de Visitantes; SR:001 - Livros de Registo de Visitantes, 1860-1888 (4 livros), e F: BP/ADE. SC. I Registo de Visitantes. SR:001 - Livros de Registo de Visitantes, 1888-1967 (3 livros).

${ }^{20}$ Nos últimos, além do nome, naturalidade e da data acrescenta-se a profissão. Entre os mais ilustres visitantes encontramos o Rei D. Fernando em 20 de Maio de 1873, acompanhado de D. Augusto, Duque de Coimbra e pelo Marquês de Pombal. No mesmo ano, em 6 de Junho de 1873, visitou a biblioteca o Núncio Apostólico, Luigi Matera, acompanhado pelo Arcebispo de Évora. Mas a grande maioria dos visitantes são obscuros cidadãos, que provêm de terras alentejanas e de outras localidades do reino e alguns estrangeiros.

${ }^{21}$ Levantamento que seria de importância para o estudo sociológico do turismo interessado pela bibliofilia. Para uma ideia da quantidade, refira-se que o livro dos anos de 1879-1888 têm 98 folhas e, se tomarmos como padrão a primeira página, onde estão registados 32 visitantes, teremos como estimativa para estes 11 anos 6.272 visitantes.

22 Para melhor leitura apresentamos os dados agrupados em períodos de quatro anos. Note-se que não há registo de Leitores para os anos entre 1911-1915 e também não há para o ano de 1920.

${ }^{23}$ No número de alfabetizados incluímos os que sabiam ler e escrever e os que só sabiam ler.

${ }^{24}$ Há registo em folhas avulsas, que provavelmente faziam parte de um livro de registo do movimento de leitores, para os anos de 1864-1868. ADE: SC: L - Requisições de Leitura, SR - 001: Livros de Requisição de Leitura; 1864-1868.

25 Arquivo Distrital de Évora - Fundo Biblioteca Pública de Évora, Secção: L - Requisições de Leitura; SR - 001 - Livros de Requisição de Leitura (1887-1902), np.

${ }^{26}$ Os dados apresentados por Gameiro confirmam este predomínio das categorias socioprofissionais referidas. Cf. Gameiro, 1997, 171)

27 Simões, 1888, p. 233.

28 Vaz, 2006, p. 79.

29 Aqui cabe também uma crítica a sua ação, porque 5 relatórios em 17 anos é muito pouco, sabendo que a partir de 1840 o Governo pretendia relatórios anuais. Mas neste domínio também Cunha Rivara não se afasta da praxis nacional que é sempre muito avessa a prestar contas, ao contrário do que acontece nos países anglo-saxónicos.

30 «Causa até vergonha mostrar ao viajante que durante o Inverno visita a Biblioteca os riquíssimos exemplares da Vita Christi (...) da Bíblia de Gutenberg, humedecidos e as vezes cobertos de bolor, e deixar-lhes ver no mesmo estado mais de 250 volumes impressos todos no século XV» (Simões, 1865, cit. in Espanca; 1981-1982, p. 243).

31 Assim, logo a seguir a Rivara foram nomeados os seguintes professores do liceu: João Rafael de Lemos (1855), Augusto Filipe Simões (1863), José Maria Queiroz Velosa (1898), António Joaquim Lopes Silva (1902), Alberto Jordão Marques da Costa (1915). CF. Espanca, ob. Cit. p. 203204.

32 ADE: F: BP/ADE, SC- E Gestão da Informação, SR01, Correspondência, 1909-1915, np.

33 Idem, 1 fl. Documento datado de Lisboa, 17-9-1914, np.

34 ADE: F: BP/ADE, SC- E Gestão da Informação SR01- Correspondência. (1863-1864), np.

35 ADE: F: BP/ADE, SC- E Gestão da Informação SR 01-Correspondência (1909-1915), np.

${ }^{36}$ Criadas pelo decreto de 2 de agosto de 1870 , em 1875 existiam em 8 localidades, mas entraram em declínio com o governo republicano tendo sido substituídas pelas primeiras bibliotecas móveis. Rebelo, 2002, p. 117 e p. 163.

\section{BIBLIOGRAFIA}

Anuário Estatístico do Reino de Portugal, Lisboa: Imprensa Nacional, 1875-1877.

Anuário Estatístico de Portugal, Lisboa: Imprensa Nacional, 1877-1921.

BARATA, P.J.S. Os Livros e o liberalismo, Lisboa: Biblioteca Nacional, 2003.

BREWER, J. Reading and readers in 18th century Britain. Cultura Revista de História e Teoria das Ideias, 1997, nº. 9, p. 159-185.

CAETANO, J.O. O Retábulo Flamengo do Museu de Évora. Cenáculo, 2007, nº 2, p. 3-10.

CARVALHO, R. História do Ensino em Portugal, Lisboa: Fundação Gulbenkian, 1981.

CERICO, P. Cunha Rivara, um Bibliotecário Romântico, Dissertação de Mestrado em Arquivos Bibliotecas e Ciências da Informação apresentada à Universidade de Évora: Évora, 2007. 
CID, I. Incunábulos da Biblioteca Pública e Arquivo Distrital de Évora: catálogo abreviado, Évora: B.P.A.D.E, 1988.

DARNTON, R. Historia de la lectura. In: BURKE, Peter (ed.), Formas de hacer Historia, Madrid, Alianza, 2003, p. 189-220.

ESPANCA, T. Subsídios para a História da Biblioteca Pública de Évora, Revista a Cidade de Évora, 1981-1982, nº 64, p. 193-267.

FARIA, M.S. de. Noticias de Portugal, Lisboa, Edições Colibri, 2003 (1ª Edição 1655).

GAMEIRO, F.L. Entre a Escola e a Lavoura. E ensino e a educação no Alentejo 1850-1910. Lisboa: Instituto de Inovação Educacional, 1997.

GARCIA, M.M. e MARTINS, L. Inventário do Arquivo Histórico da Biblioteca Nacional 1796-1950, Lisboa: Biblioteca Nacional, 1996.

MANGUEL, A. Uma História da Leitura, Lisboa: Editorial Presença, 1998.

PAWLEY, C. Reading: A Habit with a History! [on line]. Disponível em: $<$ http://www.readersadvisoronline.com/ranews/winter2009/pawley.html> [Acesso em: 15 de julho de 2015].

REBELO, C.A. A Difusão da Leitura Pública: As Bibliotecas Populares (1870-1910), Porto: Capo das Letras, 2002.

SILVA, L.M. Bibliotecas-Maravilhas de Portugal, Lisboa: Centro Atlântico, 2013.

SIMÕES, A.F. Escriptos Diversos Coligidos por ordem da secção da Arqueologia do Instituto de Coimbra, Coimbra: Imprensa da Universidade, 1888.

TENGARRINHA, J.M. Estudos de História Contemporânea de Portugal, Lisboa: Caminho, 1984.

TENGARRINHA, J.M. A Novela e o Leitor Português: Estudo de Sociologia da Leitura, Lisboa: Prelo, 1973.

VAZ, F. Os Livros e as Bibliotecas no Espólio de D. Frei Manuel Do Cenáculo, Lisboa: Biblioteca Nacional de Portugal, 2009.

VAZ, F. Os Bibliófilos Eborenses e a Biblioteca Pública (1805-1955), Diário do Sul, 7-2-2007, p. 8.

VAZ, F. A Fundação da Biblioteca Pública de Évora. In: VAZ, Francisco e CALIXTO, José A. (Ed) D. Frei Manuel do Cenáculo Construtor de Bibliotecas, Vale de Cambra: Caleidoscópio, 2006, p. 57-89.

VAZ, F. Instrução e Economia. As ideias económicas no discurso da Ilustração Portuguesa, Lisboa: Colibri, 2002.

VAZ, F. A ideia de Biblioteca na obra de D. Frei Manuel do Cenáculo. In: MEDEIROS, Filipa (Ed). Acervos Patrimoniais novas perspetivas e abordagens, Mértola: Campo Arqueológico de Mértola, 2012.

VAZ, F. A casa da sabedoria - uma leitura dos estatutos da Biblioteca Pública de Évora de 1811. Anales de Documentación, 2012, vol. 15, $\mathrm{n}^{\mathrm{o}} 2$, p. 1-12.

VEIGA, T.R. A População Portuguesa no século XIX, Porto: Edições Afrontamento, 2004.

\section{MANUSCRITOS}

Arquivo Distrital de Évora, (ADE) Fundo Biblioteca Pública de Évora, F: BP/ADE. Sc. I - registo de visitantes. 1860- 1888 (4 livros), e 1888-1967 (3 livros); Sc. L- Registos de Leitura. 